Chapman University

Chapman University Digital Commons

Pharmacy Faculty Articles and Research

School of Pharmacy

2016

\title{
Multiple siRNA Delivery Against Cell Cycle and Anti-Apoptosis Proteins Using Lipid-substituted Polyethylenimine in Triplenegative Breast Cancer and Non-Malignant Cells
}

Manoj B. Parmar

University of Alberta

Bárbara E. Arteaga Ballesteros

University of Alberta

Timothy Fu

University of Alberta

Remant Bahadur KC

University of Alberta

Hamidreza Montazeri Aliabadi

Chapman University, montazer@chapman.edu

Follow this and additional works at: http://digitalcommons.chapman.edu/pharmacy_articles

Part of the Amino Acids, Peptides, and Proteins Commons, Medicinal and Pharmaceutical Chemistry Commons, Oncology Commons, and the Other Pharmacy and Pharmaceutical Sciences Commons

\section{Recommended Citation}

Parmar, M.B., Arteaga Ballesteros, B.E., Fu, T., Bahadur KC, R., Aliabadi, H.M., Hugh, J.C., Löbenberg, R., Uludağ, H., 2016. Multiple siRNA delivery against cell cycle and anti-apoptosis proteins using lipid-substituted polyethylenimine in triple-negative breast cancer and non-malignant cells. J. Biomed. Mater. Res. n/a-n/a. doi:10.1002/jbm.a.35846 


\section{Multiple siRNA Delivery Against Cell Cycle and Anti-Apoptosis Proteins Using Lipid-substituted Polyethylenimine in Triplenegative Breast Cancer and Non-Malignant Cells}

\section{Comments}

This is the accepted version of the following article:

Parmar, M.B., Arteaga Ballesteros, B.E., Fu, T., Bahadur KC, R., Aliabadi, H.M., Hugh, J.C., Löbenberg, R., Uludağ, H., 2016. Multiple siRNA delivery against cell cycle and anti-apoptosis proteins using lipidsubstituted polyethylenimine in triple-negative breast cancer and non-malignant cells. J. Biomed. Mater. Res. n/ a-n/a. doi:10.1002/jbm.a.35846

which has been published in final form at DOI: $10.1002 / \mathrm{jbm} . \mathrm{a} .35846$. This article may be used for noncommercial purposes in accordance with Wiley Terms and Conditions for Self-Archiving.

\section{Copyright}

Wiley

\section{Authors}

Manoj B. Parmar, Bárbara E. Arteaga Ballesteros, Timothy Fu, Remant Bahadur KC, Hamidreza Montazeri Aliabadi, Judith C. Hugh, Raimar Löbenberg, and Hasan Uludag 


\section{Multiple siRNA delivery against cell cycle and anti-apoptosis}

\section{proteins using lipid-substituted polyethylenimine in triple-}

\section{negative breast cancer and non-malignant cells}

Manoj B. Parmar ${ }^{1}$, Bárbara E. Arteaga Ballesteros ${ }^{2}$, Timothy Fu $^{2}$, Remant Bahadur KC ${ }^{2}$,

Hamidreza Montazeri Aliabadi ${ }^{3}$, Judith C. Hugh ${ }^{4}$, Raimar Löbenberg $^{1}$, Hasan Uluda $^{1,2,5}$ * $^{\text {* }}$

Faculty of Pharmacy \& Pharmaceutical Sciences, University of Alberta, Edmonton, AB, Canada

${ }^{2}$ Department of Chemical \& Materials Engineering, Faculty of Engineering, University of Alberta,

Edmonton, AB, Canada

${ }^{3}$ School of Pharmacy, Chapman University, Irvine, California, United States

${ }^{4}$ Department of Laboratory Medicine \& Pathology, University of Alberta, Edmonton, Alberta, Canada

${ }^{5}$ Department of Biomedical Engineering, Faculty of Medicine \& Dentistry, University of Alberta,

Edmonton, AB, Canada

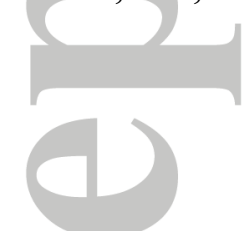

* Corresponding author: Professor Hasan Uludağ, PhD, PEng

2-021 RTF, Department of Chemical \& Materials Engineering,

Faculty of Engineering, University of Alberta, Edmonton AB T6G 2V2

Canada. E-mail: hasan.uludag@ualberta.ca

This article has been accepted for publication and undergone full peer review but has not been through the copyediting, typesetting, pagination and proofreading process which may lead to differences between this version and the Version of Record. Please cite this article as an 'Accepted Article', doi: 10.1002/jbm.a.35846 


\section{Abstract}

Conventional breast cancer therapies have significant limitations that warrant a search for alternative therapies. Short-interfering RNA (siRNA), delivered by polymeric biomaterials and capable of silencing specific genes critical for growth of cancer cells, holds great promise as an effective and more specific therapy. Here, we employed amphiphilic polymers and silenced the expression of two cell cycle proteins, TTK and CDC20, and the anti-apoptosis protein survivin to determine the efficacy of polymer-mediated siRNA treatment in breast cancer cells as well as side effects in non-malignant cells in vitro. We first identified effective siRNA carriers by screening a library of lipid-substituted polyethylenimines (PEI), and PEI substituted with linoleic acid (LA) emerged as the most effective carrier for selected siRNAs. Combinations of TTK/CDC20 and CDC20/Survivin siRNAs decreased the growth of MDA-MB-231 cells significantly, while only TTK/CDC20 combination inhibited MCF7 cell growth. The effects of combinational siRNA therapy was higher when complexes were formulated at lower siRNA:polymer ratio (1:2) compared to higher ratio (1:8) in non-malignant cells. The lead polymer (1.2PEI-LA6) showed differential transfection efficiency based on the cell-type transfected. We conclude that the lipid-substituted polymers could serve as a viable platform for delivery of multiple siRNAs against critical targets in breast cancer therapy.

\section{Key words:}

Amphiphilic polymers, siRNA delivery, breast cancer therapy, cell cycle protein, anti-apoptosis protein

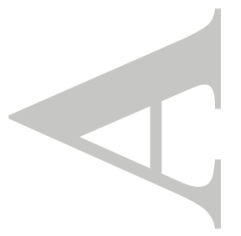




\section{Introduction}

Conventional breast cancer therapies, based on broadly acting chemotherapeutic agents, have significant limitations and side effects due to their non-specificity. More recently developed therapies mainly target estrogen receptors, progesterone receptors and human epidermal growth factor receptor 2 (HER2) of breast cancer cells to decrease the tumor growth. ${ }^{1-3}$ However, the common subtype of breast cancer, triple-negative breast cancer, occurs in $12-17 \%$ of patients, which has no expression of these receptors and will not be responsive to such therapies. ${ }^{4}$ Triple-negative breast cancer is highly metastatic, display low response to chemotherapy, has a very high recurrence rates and poor prognoses for patient survival. ${ }^{5,6}$ Targeted therapies for triple-negative breast cancer currently do not exist, so that search for novel avenues to fight against this deadly disease is warranted. A promising therapy in this regard is based on RNA interference (RNAi), where small interfering RNA (siRNA) is introduced into cells to silence the expression of aberrant genes. The latter may include proteins important for prolonged cell survival and/or causing un-checked tumor growth. ${ }^{7,8}$ Upon introduction of siRNA to a cell, siRNA is incorporated into an RNA inducing silencing complex (RISC). RISC hydrolyses the double-stranded synthetic siRNA and degrades passenger strand while having the guide strand into the RISC assembly. ${ }^{8,9}$ The guide strand of siRNA directs the whole complex specifically towards its targeted mRNA. The siRNA-RISC complex binds to the targeted mRNA, and either cleave the mRNA or block the translation process, which results into silencing of specific target. ${ }^{9}$ The major issue associated with siRNA therapy is the delivery. Since the siRNA is highly labile due to endogenous nucleases and its negative charge, its entry into the cell on its own is almost impossible. ${ }^{10,11}$ The siRNA, therefore, needs a carrier that can deliver it into the cells by neutralizing its anionic charge, and protect it from extracellular degradation. We have synthesized a library of cationic polymeric carriers for such purpose, which is based on low molecular weight polyethylenimines (PEI). ${ }^{12,13}$ PEIs were 
substituted with different lipidic moieties that help siRNA/polymer complexes to penetrate the plasma membrane and improve the uptake of complexes. ${ }^{13,14}$ Cationic lipid-substituted PEIs provide protection to siRNA as well as facilitate its delivery into the cell so that siRNA can be assembled with RISC.

Controlled cell division and multiplication involve many proteins in a series of events, commonly known as the cell cycle. The deregulation of the cell cycle is one of the hallmarks of cancer, where cell cycle proteins are mostly upregulated. ${ }^{15,16}$ Due to aberrant expression of cell cycle proteins, control over proliferation and multiplication of the cells is lost, resulting in a cancerous growth. If the expression of these up-regulated cell cycle proteins is silenced by siRNA therapy, the proliferation of malignant cells may be decreased and tumor growth can be halted. Here, we have targeted two cell cycle proteins, monopolar spindle 1 (MPS1) and cell division cycle protein 20 (CDC20) to silence their expression by siRNA. MPS1 is more commonly known as TTK protein kinase since it is able to phosphorylate tyrosine, serine and threonine residues of a substrate. It is exclusively associated with the cell proliferation. ${ }^{17}$ It aligns chromosomes at the centromere and is required for the duplication of centrosome during mitosis. ${ }^{18}$ TTK is a critical mitotic checkpoint protein for accurate segregation of chromosomes during mitosis, and it is up-regulated in tumorigenesis. ${ }^{19-22}$ A related cell cycle protein, CDC20, activates the anaphase-promoting complex (APC) in the cell cycle during mitosis, which initiates chromatid separation and entrance of the cell division into anaphase. ${ }^{23}$ The reports have shown that inhibition of TTK protein disrupts the CDC20-MAD2 (mitotic arrest deficient 2; inhibitor of CDC20) complexation, causing premature activation of APC that accelerates anaphase during mitosis. ${ }^{24,25}$ Therefore, silencing TTK along with CDC20 could be a promising strategy to achieve a synergistic reduction in malignant cell growth by combinational siRNA therapy.

The cell cycle process is often coordinated with the apoptosis machinery to maintain tissue homeostasis. ${ }^{26}$ Apoptosis is a tightly regulated process of programed cell death that is executed by activation of caspases. ${ }^{27}$ The delicate balance between pro-apoptotic and anti-apoptotic proteins maintains the integrity of normal cell, and this balance is often shifted in favor of anti-apoptotic 
proteins in transformed cells to allow cells to resist drug therapy and to maintain an over-proliferative state. $^{28-30}$ The member of inhibitor of apoptosis proteins (IAP), survivin is known to inhibit caspase activation and block apoptosis. Survivin is up-regulated in many cancer types, but is completely absent in terminally differentiated cells. ${ }^{31}$ Transcriptional silencing of survivin may provide an excellent therapeutic opportunity as the discrimination between malignant and normal cells can be achieved. The evidences suggest a role for survivin in spindle checkpoint ${ }^{32,33}$ and, therefore, targeting survivin along with cell cycle proteins by siRNA may lead to additive effect(s) to retard tumor growth.

In this study, we first determined the most effective polymeric carrier for siRNA delivery, and evaluated the efficacy of various TTK siRNAs targeting different locations of TTK transcripts using that effective polymeric carrier. We then evaluated the combinational siRNA therapy with TTK, CDC20 and survivin siRNAs in breast cancer cells. We hypothesize that siRNA combinations targeting mediators of abnormal cell cycle progression such as TTK, CDC20 and survivin may provide synergistic therapeutic effect on breast cancer cells. The effect of this combinational siRNA therapy was also evaluated in normal cells, including breast, endothelial and bone marrow stromal cells.

\section{Materials and Methods}

\section{Materials}

The amines of low molecular weight PEIs (0.6, 1.2 and $2.0 \mathrm{kDa})$ were substituted with linoleic acid via N-acylation (PEI-LA) and the degree of substitution was determined by NMR Spectroscopy as previously described. ${ }^{34,35}$ MTT [3-(4 5-dimethylthiazol-2-yl)-2 5-diphenyltetrazolium] and dimethyl sulfoxide (DMSO) were purchased from Sigma-Aldrich (St. Louis, MO). Hank's Balanced Salt Solution (HBSS) was prepared in-house.

TTK-1 (Cat. No. SI02223207), TTK-2 (Cat. No. SI02223214), TTK-3 (Cat. No. SI03062745) and TTK-4 (Cat. No. SI04898747) siRNAs were ordered from Qiagen (Valencia, CA), and TTK-5 
(Cat. No. HSC.RNAI.N001166691.12.1) and TTK-6 siRNAs (Cat. No. HSC.RNAI.N001166691.12.2) were purchased from IDT (Coralville, IA). Negative control scrambled siRNA (Cat. No. DS NC1), CDC20 siRNA (Cat. No. HSC.RNAi.N001255.12.1) and survivin siRNA (Cat. No. HSC.RNAI.N001012271.12.1) were ordered from IDT. The 6-Carboxyfluorescein (FAM) labeled scrambled siRNA was purchased from IDT. Primers for TTK (forward: GCCCGAAAAGTAATACAGAGCAGA; reverse: GATGTTGATATTGGTGGTGACTGT), CDC20 (forward: CGCTATATCCCCCATCGCAG; reverse: GATGTTCCTTCTTGGTGGGC), survivin (forward: TGAGAACGAGCCAGACTTGG; reverse: ATGTTCCTCTATGGGGTCGT) and Glyceraldehyde 3-phosphate dehydrogenase (GAPDH; forward: TCACTGTTCTCTCCCTCCGC; reverse: TACGACCAAATCCGTTGACTCC) were supplied by IDT.

\section{Cell models}

The triple-negative breast cancer MDA-MB-231 cells and MCF7 (estrogen- and progesteronepositive) cells were cultured in DMEM medium with $10 \%$ fetal bovine serum (FBS), $100 \mathrm{U} / \mathrm{mL}$ penicillin and $100 \mu \mathrm{g} / \mathrm{mL}$ streptomycin. MDA-MB-231 and MCF7 cells were generous gifts from Dr. Michael Weinfeld, Department of Oncology, University of Alberta, and Dr. Afsaneh Lavasanifar, Faculty of Pharmacy and Pharmaceutical Sciences, University of Alberta, respectively. The normal breast cells MCF10A were cultured in DMEM/F12 medium with 500 ng/mL hydrocortisone, 20 ng/mL human epidermal growth factor (hEGF), $0.01 \mathrm{mg} / \mathrm{mL}$ human insulin, $100 \mathrm{ng} / \mathrm{mL}$ cholera toxin, 5\% horse serum, $100 \mathrm{U} / \mathrm{mL}$ penicillin and $100 \mu \mathrm{g} / \mathrm{mL}$ streptomycin. MCF10A cells were gift from Dr. Judith Hugh, Department of Laboratory Medicine and Pathology, University of Alberta. Human umbilical vein endothelial cells (HUVEC), generous gift from Dr. Janet A. W. Elliott, Department of Chemical and Materials Engineering, University of Alberta, were cultured on rat tail type I collagen coated culture flask with EGM-2 medium that was supplied with manufacturer's growth factor bulletkit, 10\% FBS, $100 \mathrm{U} / \mathrm{mL}$ penicillin and $100 \mu \mathrm{g} / \mathrm{mL}$ streptomycin. Human bone marrow stromal 


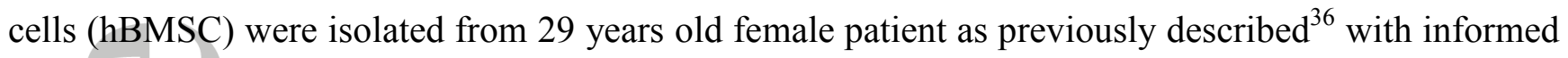
consent and approval from the Research Ethics Board, University of Alberta. hBMSC cells were cultured in DMEM/F12 medium with 10\% FBS, $20 \mathrm{ng} / \mathrm{mL}$ basic fibroblast growth factor (bFGF), 100 $\mathrm{U} / \mathrm{mL}$ penicillin and $100 \mu \mathrm{g} / \mathrm{mL}$ streptomycin. All cell-lines were maintained at $37^{\circ} \mathrm{C}$ and $95 / 5 \%$ air/ $\mathrm{CO}_{2}$.

\section{Screening of polymers and preparation of siRNA/polymer complexes}

To determine most effective polymeric carrier for siRNA delivery, a library of synthesized polymers (Supplementary Table 1) was screened with TTK-1 and CDC20 siRNAs, and scrambled siRNA as a negative control. The inhibition of cell growth was assessed with the MTT assay after 72 hrs of siRNA transfection. The siRNAs were typically used at $40 \mathrm{nM}$ concentration with 1:6 siRNA:polymer ratio. The lipid-based commercial carrier, Lipofectamine ${ }^{\circledR} 2000$ (Thermo Fisher Scientific, Waltham, MA) was also used in the screening with 1:1 siRNA:Lipofectamine ratio. The siRNA/polymer complexes were prepared in $150 \mathrm{mM} \mathrm{NaCl}$ by allowing $30 \mathrm{~min}$ of incubation time after adding polymer into siRNA for their interaction with each other to form complexes. The complexes were added to cells after $30 \mathrm{~min}$ of incubation at room temperature. After 72 hrs of treatment, MTT was added to the cells at $1 \mathrm{mg} / \mathrm{mL}$ final concentration in HBSS. The cells were incubated for $1 \mathrm{hr}$ at $37{ }^{\circ} \mathrm{C}$ and $5 \% \mathrm{CO}_{2}$. During this incubation, soluble MTT is transformed into insoluble formazan crystals due to the activity of mitochondrial dehydrogenase enzymes, giving a measure of cellular activity. ${ }^{37}$ DMSO was added to the well to dissolve the formazan crystals formed because of cellular activity of live cells. The optical density (OD) was measured at $570 \mathrm{~nm}$ and the ODs were summarized as a percentage of cell growth based on non-treated cells (taken as $100 \%$ cell growth).

\section{Size and $\zeta$-potential of siRNA/polymer complexes}

John Wiley $\not \&$ Sons, Inc.

This article is protected by copyright. All rights reserved. 
To characterize siRNA/polymer complexes based on different degree of lipid-substitutions in $1.2 \mathrm{kDa}$ PEI, hydrodynamic diameter (Z-average) and surface charge ( $\zeta$-potential) of these complexes were determined in $\mathrm{ddH}_{2} \mathrm{O}$ through dynamic light scattering (DLS) and electrophoretic light scattering (ELS) using Zetasizer Nano ZS (Malvern, UK). The complexes were prepared as described above with 0.6 $\mu \mathrm{g}$ of scrambled siRNA at $1: 6$ and 1:1 siRNA:polymer and siRNA:Lipofectamine ratio, respectively, and were diluted to $1 \mathrm{~mL} \mathrm{ddH}_{2} \mathrm{O}$ before each measurement. The size and $\zeta$-potential of siRNA/polymer complexes were characterized based on different siRNA:polymer ratios as well. Native 1.2 kDa PEI and 1.2PEI-LA6 were employed at 1:2, 1:4 and 1:8 siRNA:polymer ratios to determine the size and $\zeta$-potential of complexes as described above.

\section{siRNA uptake by flow cytometry}

To determine the delivery efficiency of lipid-substituted PEIs based on different degree of LA substitutions, MDA-MB-231 cells were transfected with FAM-labeled siRNA at 40 nM with 1:6 siRNA:polymer ratio. Lipofectamine ${ }^{\circledR} 2000$ (Thermo Fisher Scientific) was used at 1:1 siRNA:Lipofectamine ratio. Non-labeled scrambled siRNA was used as a negative control. Cells were trypsinized after $24 \mathrm{hrs}$ of siRNA transfection and fixed with $3.7 \%$ formaldehyde. The uptake of siRNA was quantified using BD LSRFortessa ${ }^{\mathrm{TM}}$ cell analyzer (Becton Dickinson, Franklin Lakes, NJ). The mean fluorescence of the recovered cell population and the percentage of cells showing FAMfluorescence were determined after gating of the cell population as such that auto-fluorescence of untreated cells represented $\sim 1 \%$ of the total cell population.

To inyestigate the potential of the lead polymer 1.2PEI-LA6 to deliver siRNA, MDA-MB-231 and MCF7 cells were transfected with FAM-labeled siRNA at $30 \mathrm{nM}$ with 1:2, 1:4, and 1:8 siRNA:1.2PEI-LA6 ratios. The uptake study by flow cytometry was also performed in normal cells, MCF10A, HUVEC and hBMSC as described above to determine how effectively siRNA was delivered by the polymer to normal cells. 


\section{Targeting TTK with various siRNAs}

TTK siRNAs targeting different locations of the gene were used to determine their efficacy by MTT assay in MDA-MB-231 and MCF7 cells using 20, 40 and $60 \mathrm{nM}$ siRNA concentrations with 1:4 siRNA:polymer ratio. After $72 \mathrm{hrs}$ of siRNA transfections, MTT assay was performed as described above to measure the inhibition of MDA-MB-231 and MCF7 cells growth by various TTK siRNAs.

\section{Reverse transcription - quantitative PCR (RT-qPCR)}

The MDA-MB-231 and MCF7 cells were transfected by TTK-1 and CDC20 siRNAs at $60 \mathrm{nM}$ with 1:4 siRNA:1.2PEI-LA6 ratio. Total RNA was isolated from cells after 24 and 48 hrs of treatment using TRIzol reagent (Invitrogen, Carlsbad, CA). One microgram of total RNA was converted into cDNA using M-MLV reverse transcriptase (Invitrogen) according to manufacturer's instruction. The quantitative PCR (qPCR) was performed by taking $15 \mathrm{ng}$ of cDNA from each sample using SYBR Green qPCR Mastermix (Molecular Biology Service Unit, Department of Biological Sciences, University of Alberta, Edmonton, AB) and StepOne Real-Time PCR System (Applied Biosystems, Foster City, CA) based on the recommendations of manufacturer. Primers were designed using NCBI Primer-BLAST (http://www.ncbi.nlm.nih.gov/tools/primer-blast/) in such a way that at least one primer (forward or reverse) spans the exon-exon junction of a gene so that the amplification of contaminating genomic DNA or hetero-nuclear RNA by PCR can be avoided. GAPDH was used as a reference gene in $\mathrm{RT}-\mathrm{qPCR}$ and template cDNA was omitted from $\mathrm{qPCR}$ reaction as a negative control. The qPCR results were analyzed using $2^{-\Delta \Delta C}$ method and presented as relative quantity of transcripts. The qPCR conditions comprised an initial denaturation step for $10 \mathrm{~min}$ at $95.0{ }^{\circ} \mathrm{C}$, followed by 40 cycles at $95.0^{\circ} \mathrm{C}$ for $15 \mathrm{~s}$ (denaturation), and annealing and elongation at $60{ }^{\circ} \mathrm{C}$ for $1 \mathrm{~min}$.

\section{Combinational siRNA therapy}

John Wileyg\& Sons, Inc.

This article is protected by copyright. All rights reserved. 
Combinational siRNA delivery was performed in MDA-MB-231 and MCF7 using TTK-1, CDC20 and survivin siRNAs at $30 \mathrm{nM}(15 \mathrm{nM}$ each) total siRNA concentration with 1:2, 1:4 and 1:8 siRNA:1.2PEI-LA6 ratio. After $72 \mathrm{hrs}$ of siRNA transfection, MTT assay was performed as described above to determine the efficacy of combinational siRNA therapy. Induction of apoptosis in MDA-MD231 cells by combinational siRNA therapy was determined by caspase activity assay. To investigate caspase activity, total protein from MDA-MB-231 cells was isolated by applying freeze-thaw cycle 3times after 72 hrs of combinational siRNA transfection. Cell-debris was removed from isolated protein by centrifugation at $10,000 \mathrm{~g}$ for $5 \mathrm{~min}$. Total protein was incubated for $2 \mathrm{hrs}$ with the fluorogenic substrate (Ac-DEVD-AFC; Cat. No. ALX-260-032, Enzo Life Sciences, Farmingdale, NY) at $37^{\circ} \mathrm{C}$ and the fluorescence of the substrate was measured at 390/510 $\mathrm{nm}$ excitation/emission. The fluorescence was normalized per $\mu \mathrm{g}$ of protein after determining the concentration of total protein for each sample by Pierce ${ }^{\mathrm{TM}}$ BCA Protein Assay Kit (Cat. No. 23227, Thermo Fisher Scientific) according to manufacturer's instructions. The caspase activity was presented as a percentage of activity based on non-treated cells (taken as 100\% activity).

The validity of combinational siRNA therapy at mRNA transcript levels was determined by RT-qPCR. MDA-MB-231 and MCF7 cells were transfected with 30 and $60 \mathrm{nM}$ total combinational siRNA concentration at 1:4 siRNA:1.2PEI-LA6 ratio. After 24 hrs of transfection, RNA was isolated and converted into cDNA as described above, which was used to perform qPCR.

\section{siRNA delivery to non-malignant cells}

Combinational siRNAs against TTK-1, CDC20 and survivin were also delivered to normal cells, MCF10A, HUVEC and hBMSC to determine the side effects of siRNA therapy. MTT assay was performed to determine the inhibition of normal cell growth by siRNA transfection at $30 \mathrm{nM}(15 \mathrm{nM}$ each) total siRNA concentration with 1:2, 1:4 and 1:8 siRNA:1.2PEI-LA6 ratio. Specific cell growth inhibition by combinational siRNA therapy compared to scrambled siRNA in all cell-lines was 
calculated by removing cell growth inhibition of scrambled siRNA from specific siRNA treated cells and the values were presented as a heat-map.

\section{Statistical analysis}

All results were presented as mean + standard deviation. Results were analyzed by unpaired Student's t-test, where an asterisk $\left(^{*}\right)$ indicated significantly different groups in figures. The significance $(p<0.05)$ was typically determined by comparing specific siRNA-treated groups to that of scrambled siRNA-treated groups.

\section{Results}

\section{Screening for effective carriers}

Several LA-substituted PEIs were used to screen for the best polymeric carrier by determining inhibition of MDA-MB-231 cell growth with the TTK-1 and CDC20 siRNAs (Figure 1). The synthesized polymers were designated based on the molecular weight of PEI (0.6, 1.2 and 2.0 kDa) backbone used for modification, followed by the substituted lipid moiety and the feed ratio of lipid/PEI during the synthesis of the polymers (see Supplementary Table 1 for more detailed info). Lipofectamine $^{\circledR} 2000$, a widely used commercial carrier, was employed as a reference carrier that was unable to inhibit cell growth with TTK-1 siRNA while it inhibited cell growth $\sim 50 \%$ with the CDC20 siRNA. Many synthesized polymeric carriers were not effective to inhibit cell growth with TTK-1 siRNA, except 1.2PEI-LA6 that inhibited cell growth significantly (Figure 1A). With CDC20 siRNA delivery, 1.2PEI-LA6, 2.0PEI-LA6 and 2.0PEI-LA9 polymers were able to decrease cell growth significantly (Figure 1B). The 1.2PEI-LA6 was the most effective polymer as it inhibited $\sim 80 \%$ of cell growth with CDC20 siRNA and, since it was also effective with TTK-1 siRNA, it was used to carry 
out the rest of the studies. The 1.2PEI-LA8 was quite toxic in MDA-MB-231 cells as the growth of scrambled siRNA treated cells was inhibited drastically.

The siRNA/polymer complexes were characterized based on different degree of lipidsubstitutions in 1.2 kDa PEI by measuring size and surface charge (Figure 2A). The size of complexes with Lipofectamine ${ }^{\circledR} 2000$ was $\sim 100 \mathrm{~nm}$, while it was less with native $1.2 \mathrm{kDa}$ PEI without any modification $(\sim 70 \mathrm{~nm})$. Substitution of PEI with linoleic acid (1.2PEI-LA0.5) increased the complex size $(\sim 127 \mathrm{~nm})$, and complex size gradually decreased as the LA substitution in PEI was increased from 1.2PEI-LA0.5 to 1.2PEI-LA8 $(\sim 70 \mathrm{~nm})$. On the other hand, $\zeta$-potential of complexes with Lipofectamine ${ }^{\circledR} 2000$ was $-21 \mathrm{mV}$, and initial (minimal) substitution of LA in PEI decreased surface charge from $\sim 17 \mathrm{mV}(1.2 \mathrm{PEI}-\mathrm{LA} 0)$ to $10 \mathrm{mV}$ (1.2PEI-LA0.5). The $\zeta$-potential of complexes gradually increased as the substitution of LA has increased in PEI from 1.2PEI-LA0.5 $(\sim 10 \mathrm{mV})$ to 1.2PEI-LA6 (28.8 mV), after which 1.2PEI-LA8 showed a significant drop in the surface charge $(\sim 15 \mathrm{mV})$.

The uptake of siRNA/polymer complexes was determined for different LA substituted PEIs (Figure 2B). Lipofectamine ${ }^{\circledR} 2000$ successfully delivered siRNA to MDA-MB-231 cells and transfected $\sim 80 \%$ cell population. As expected, non-modified $1.2 \mathrm{kDa}$ PEI was not able to deliver siRNA at all to MDA-MB-231 cells. Similarly, siRNA uptake was not observed when it was delivered with 1.2PEI-LA0.5, 1.2PEI-LA2 and 1.2PEI-LA4. Polymers 1.2PEI-LA1 and 1.2PEI-LA8 delivered siRNA at some extent as higher mean fluorescence compared to 1.2PEI-LA0.5, 1.2PEI-LA2 and 1.2PEI-LA4 was observed in these cells. However, the transfection efficiency was lower as only 53 and $38 \%$ of cells were transfected with 1.2PEI-LA1 and 1.2PEI-LA8, respectively. The 1.2PEI-LA6 was the most effective polymer as the highest mean fluorescence was detected and $97 \%$ cell population were transfected with this polymer.

\section{Delivery of TTK siRNAs to breast cancer cells}


The efficacy of various TTK siRNAs targeting different locations of the mRNA was determined by inhibition of MDA-MB-231 and MCF7 cell growth (Figure 3). TTK-1, TTK-2, TTK-3 and TTK-4 siRNAs at $20 \mathrm{nM}$ has decreased the MDA-MB-231 cell growth by 10-40\%, while $40 \mathrm{nM}$ of siRNA inhibited cell growth by 70-90\%. Similarly, $60 \mathrm{nM}$ of TTK siRNAs decreased MDA-MB231 cell growth significantly compared to scrambled siRNA. CDC20 siRNA was able to inhibit the MDA-MB-231 cell growth drastically at all the concentrations used. Furthermore, MCF7 cells were not responsive to TTK-1, TTK-2, TTK-3, TTK-4 and CDC20 siRNAs at all concentrations.

The TTK-5 and TTK-6 siRNAs decreased the MDA-MB-231 cell growth $\sim 90 \%$ at $40 \mathrm{nM}$ siRNA, while no significant difference between TTK-5 and TTK-6 siRNA treated cells and scrambled siRNA treated cells was found at $60 \mathrm{nM}$ siRNA (Figure 3). TTK-5 siRNA decreased MCF7 cell growth $20-40 \%$ at 40 and $60 \mathrm{nM}$, while TTK-6 siRNA was not able to inhibit the cell growth significantly compared to scrambled siRNA.

To determine the functionality of TTK-1 and CDC20 siRNAs at the transcripts level, RT-qPCR was performed for MDA-MB-231 and MCF7 cells. Significant reduction in the levels of TTK and CDC20 mRNA transcripts was found using TTK-1 and CDC20 siRNAs after 24 and 48 hrs of siRNA transfection (Figure 4). RT-qPCR confirmed that the siRNAs against TTK protein were effective in obtaining the desired silencing and the polymeric carrier was able to deliver siRNAs successfully into the cells.

\section{Combinational siRNA delivery against TTK, CDC20 and survivin}

Combinational siRNA therapy was performed in MDA-MB-231 and MCF7 cells to determine if a synergistic effect can be achieved with carefully selected combination of siRNAs. A relatively low concentration of siRNA (total $30 \mathrm{nM} ; 15 \mathrm{nM}$ siRNA each) was chosen for this purpose. The siRNA delivery against single targets at these concentrations $(15 \mathrm{nM}$ specific siRNA $+15 \mathrm{nM}$ scrambled siRNA) served as a reference treatment. The siRNA against TTK (using TTK-1 siRNA; referred as 
TTK siRNA hereafter) and CDC20 alone was not effective in MDA-MB-231 as no inhibition of cell growth was found due to very low concentration of siRNA. However, survivin siRNA alone decreased cell growth by $\sim 25 \%$ at $1: 4$ siRNA:polymer ratio. The synergistic effect of dual therapy was detected with TTK-CDC20 and CDC20-survivin siRNA combination in MDA-MB-231 cells at 1:4 ratio as the cell growth was inhibited by $\sim 30 \%$ and $\sim 45 \%$, respectively compared to scrambled siRNA as well as individual targeted siRNAs (Figure 5A). The synergism was not detected for dual therapy at 1:2 and 1:8 siRNA:polymer ratios. Caspase activity assay was performed using MDA-MB-231 cells to investigate the initiation of apoptosis in the cell by combinational siRNA therapy. No increase in the caspase activity was found with TTK siRNA alone, while CDC20 and survivin siRNAs showed drastic increase in the caspase activity (Supplementary Figure 1). Similarly, all siRNA combinations confirmed the initiation of apoptosis in MDA-MB-231 cells as caspase activity was found significantly higher.

No significant decrease in MCF7 cell growth was found by individual siRNA against TTK, CDC20 and survivin at $30 \mathrm{nM}$ total concentration. TTK-CDC20 combination has shown synergistic effect as $\sim 25 \%$ of cell growth was inhibited by these siRNAs at 1:4 ratio in MCF7 cells compared to scrambled siRNA as well as individual TTK and CDC20 siRNAs (Figure 5B).

The efficacy of the combinational siRNA therapy was also determined by RT-qPCR in MDAMB-231 and MCF7 cells at 30 and $60 \mathrm{nM}$ total siRNAs (Figure 6). The amount of mRNA transcripts for each targeted protein was significantly decreased after individual and dual siRNA delivery, which confirmed that TTK, CDC20 and survivin siRNAs were able to silence its target upon successfully delivered by polymeric carrier.

\section{Cellular uptake of siRNA in breast cancer and non-malignant cells}

To investigate how effectively 1.2PEI-LA6 delivers siRNA into the cells, the uptake of FAMlabeled siRNA was performed in breast cancer MDA-MB-231 and MCF7 cells and normal cells, 
MCF10A, HUVEC, hBMSC (Figure 7). No autofluorescence of the complexes was detected as the mean fluorescence and FAM-positive population of non-treated and non-labeled scrambled siRNA treated cells were similar (data not shown). Based on the mean fluorescence of MDA-MB-231 cells, the cellular uptake of siRNA increased with higher siRNA:polymer ratio $(1: 4$ and 1:8) compared to lower ratio $(1: 2)$. However, no major difference was found in MDA-MB-231 cellular uptake between 1:4 and 1:8 ratio. Similarly, an equivalent uptake of siRNA was found at all ratios in MCF7 cells, which was quite low compared to MDA-MB-231 cells.

The cellular uptake of siRNA at 1:2 and 1:4 siRNA:polymer ratios was similar in normal breast MCF10A cells, while the uptake was significantly increased at 1:8 ratio (Figure 7). No difference was evident among all siRNA:polymer ratios in the cellular uptake of HUVEC and hBMSC cells. Considering the cellular uptake by breast cancer and normal cells, 1:4 siRNA:polymer ratio could be better formulation of siRNA and 1.2PEI-LA6 due to quite low siRNA delivery efficiency of polymer at this ratio in normal cells compared to MDA-MB-231 cells.

\section{Targeting TTK, CDC20 and survivin in non-malignant cells}

The TTK, CDC20 and survivin siRNAs were delivered to normal cells to determine possible effects of siRNA therapy on non-malignant cells. Normal breast cells MCF10A were quite responsive to siRNAs at $1: 2$ and $1: 4$ ratios as $20-40 \%$ of cell growth was inhibited with individual or combinational siRNAs (Figure 8A). However, 1:8 ratio of siRNA was not at all effective to MCF10A cells. No inhibition of HUVEC cell growth was found with complexes formed at higher ratios (1:4 and 1:8). However, complexes at 1:2 ratio inhibited HUVEC cell growth by 20-50\% with individual/combined CDC20 and survivin siRNAs (Figure 8B). The hBMSC cell growth was significantly inhibited by the CDC20 siRNA at 1:2 and 1:4 ratios whether it was delivered individually or in combination (Figure $8 \mathrm{C}$ ). However, 1:8 ratio was unable to decrease the cell growth by all siRNAs. Specific cell growth inhibition by combinational siRNA therapy is presented for breast cancer 
and normal cells in Figure 8D. Overall, complexes formulated at higher siRNA:polymer ratio showed the least siRNA effect on non-malignant cells and, therefore, the ratio of siRNA:polymer will need to be chosen carefully to decrease the side effects of siRNAs on normal cells.

\section{Discussion}

The RNAi has become a viable approach in the last decade to develop a targeted cancer therapy, where a specific protein can be silenced to achieve a reduction in tumor growth. ${ }^{7,8}$ The siRNA therapy has its limitations, and one of them is the development of a non-toxic carrier that can successfully deliver siRNA into the cell. We evaluated a library of polymeric carriers based on low molecular weight PEIs $(0.6,1.2$ and $2.0 \mathrm{kDa})$ to deliver siRNA as high molecular weight branched $(>25 \mathrm{kDa})$ and linear $(>750 \mathrm{kDa})$ PEIs possess unacceptable cytotoxicity. ${ }^{38}$ PEI can escape the endosomal compartment due to its inherent 'proton-sponge' effect so that siRNA can be effectively delivered into cytoplasm after the cellular uptake of siRNA/polymer complexes. ${ }^{38}$ The cellular uptake of siRNA using low molecular weight PEIs is quite low ${ }^{34,35}$ and no cellular uptake of siRNA was observed with non-modified 1.2 kDa PEI (Figure 2B). Therefore, we substituted the amines of PEIs with lipidic moieties to improve the delivery of siRNA. The lipidic moieties presumably improves chemical compatibility of siRNA/polymer complexes with cell membrane so that siRNA uptake can be increased significantly. ${ }^{14}$ In addition, the degree of substitutions in PEI plays a major role for uptake of complexes. No siRNA uptake was observed with low LA substitutions (Figure 2B), and high LA substituted PEI showed higher toxicity (Figure 1). The relationship between the uptake and LA substitution was not monotonous, since a critical degree of substitution ( $>2 \mathrm{LA} / 1.2 \mathrm{PEI})$ was required to enable uptake of siRNA complexes. An optimal LA substitution in PEI is necessary to have higher uptake and less cytotoxicity, and 1.2PEI-LA6 seemed to have both characteristics based on cellular uptake and inhibition of cell growth. Moreover, physicochemical characteristics of the complexes play 
an important role in the uptake of siRNA as well. Hydrodynamic size of complexes with 1.2PEI-LA6 has decreased significantly (Figure 2A), while $\zeta$-potential has dramatically increased compared to other LA substituted polymers, which could have contributed to better uptake of siRNA with 1.2PEI-LA6 compared to other polymers. Among many synthesized polymer, 1.2PEI-LA6 was the most effective polymer that inhibited cell growth drastically when it was used to deliver CDC20 siRNA (Figure 1), which was consistent with uptake results (Figure 2). Several other polymers inhibited MDA-MB-231 cell growth as well with CDC20 siRNA. However, only 1.2PEI-LA6 showed significant decrease in the cell growth with TTK siRNA. The efficacy of growth inhibition by TTK delivery, however, was quite low compared to CDC20 siRNA, which suggests that CDC20 may be more potent target for silencing compared to TTK. This is not surprising since CDC20 was previously identified from a siRNA library screen, where we selected the most efficacious siRNA from a library of 169 siRNAs. ${ }^{39}$ The polymers derived from the 0.6 kDa PEI were generally not effective, presumably due to smaller size and relatively less efficient binding to siRNA, and higher LA substitutions on 1.2 and $2.0 \mathrm{kDa}$ PEIs generally led to more effective growth inhibition.

We targeted TTK protein in this study with various siRNAs since the up-regulation of this gene in many cancer types was reported leading to uncontrolled proliferation of those cancer cells. ${ }^{21,22}$ As TTK is associated with cell proliferation, it has been silenced in pancreatic, prostate and liver cancers by siRNA using commercially available carriers to decrease cell proliferation. ${ }^{22,40-42}$ In this study, we showed that TTK is also a viable target in breast cancer and delivering the TTK siRNA using polymeric carrier would lead to decrease in the breast cancer cell growth (Figure 3 ). The results were confirmed at transcripts level as well by RT-qPCR (Figure 4). We used six different siRNAs against TTK to determine the efficacy of each siRNA. The outcome was expected to depend on how thermodynamically asymmetric siRNA is and where siRNA is targeting in the gene. ${ }^{43}$ Based on the thermodynamic asymmetry of siRNA, the components of RISC bind to siRNA and the selection of guide strand is made. ${ }^{44}$ The various siRNAs for the same gene, therefore, should have different 
efficiency of silencing its target. TTK-5 and TTK-6 siRNAs that were supplied by IDT were 27 base pair dicer-substrate siRNA, which has a longer nucleotide sequence compared to regular 21 base pair siRNAs. Dicer-substrate siRNA interacts with the dicer enzyme before its incorporation into the RISC assembly, which may lead to increased potency by engaging to natural siRNA processing pathway. ${ }^{45}$ However, no difference in the potency of 21 and 27 base pairs siRNAs was observed for TTK siRNAs, and inhibition of MDA-MB-231 cell growth was found at some extent with all six siRNAs (Figure 3). Previously, we have observed high efficacy with dicer-substrate siRNA against CDC20 compared to regular 21 base pair siRNA, ${ }^{39}$ but it seems that the relative efficiency might depend on the target and/or exact sequence (siRNA binding site in a gene) of the siRNA. MCF7 cells were not as responsive as MDA-MB-231 to TTK siRNAs despite displaying effective silencing (Figure 4), which suggests that MCF7 cells may not critically rely on TTK protein for its survival and may have found an alternative protein to undertake cell division.

CDC20 has a key role during mitosis to activate APC that leads cells from metaphase to anaphase. We have validated the efficacy of various siRNAs against CDC20 previously in two breast cancer models (MDA-MB-435 and MDA-MB-231 cells). ${ }^{39}$ CDC20 silencing showed significant cell death at $40 \mathrm{nM}$ of siRNA in MDA-MB-231 cells (Figure 1B), while it displayed poor efficacy at 15 nM of siRNA in both MDA-MB-231 and MCF7 cells (Figure 5). Survivin siRNAs employed here was dicer-substrate siRNAs and has shown increased potency in MDA-MB-231 cells at 15 nM concentration (Figure 5A). Since survivin has been shown to be a critical target for cancer therapy as well, the siRNA against survivin was applied to breast cancer cells and the efficacy of targeting survivin was validated previously. ${ }^{46}$

Silencing the expression of two essential proteins simultaneously is a promising strategy as the chances of survival for malignant cells could drastically be decreased. Not only the synergistic effect of the combinational therapy can be achieved, but also the doses of siRNAs can be lowered to have less side effects on non-malignant cells. We have targeted the cell cycle proteins, TTK and CDC20 
with siRNAs and observed a synergism in the therapy at low doses of siRNAs. RT-qPCR confirmed the functionality of combinational TTK-CDC20 siRNA therapy at transcripts level (Figure 6) so that we do not seem to be overloading the RISC-mediated silencing machinery with dual siRNA delivery. Elevation in TTK transcripts was consistently observed in MDA-MB-231 cells upon silencing CDC20 individually or with combination, which suggests that cells may have upregulated TTK expression upon detecting loss of CDC20 protein. Upon depletion of cell cycle proteins during cell proliferation, cell cycle is arrested until the error in the cell cycle is corrected. ${ }^{47}$ If the essential proteins for cell cycles are missing, especially TTK and CDC20 that participate in mitosis, the error cannot be corrected and pathways for cell death is expected to be initiated. The mitotic catastrophe ${ }^{48}$ or initiation of apoptotic pathway by caspase activation (cell death mechanisms) may have played role upon depletion of TTK and CDC20 in breast cancer cells as the cell death (Figure 5) and the elevation in caspase activity (Supplementary Figure 1) were evident with combinational siRNA therapy against these cell cycle proteins. Several lines of evidence suggest that cell cycle and anti-apoptosis proteins have conjunctional roles during cell division. ${ }^{49,50}$ Moreover, arrested cell cycle due to inhibition of a specific cell cycle protein could increase the production of anti-apoptosis protein to block the apoptotic pathway that may have been initiated in order to overcome cell cycle arrest. Therefore, targeting antiapoptosis protein such as survivin with TTK and CDC20 seems appropriate to have a synergism in combinational siRNA delivery. The synergistic effect of the combinational CDC20/survivin siRNA therapy was evident in MDA-MB-231 cells (Figure 5A).

The siRNA:polymer ratio plays a major role for the efficacy of siRNA treatment. The synergistic effect of dual siRNA therapy was not observed at lower 1:2 siRNA:polymer ratio in MDAMB-231 cells (Figure 5A) due to poor uptake of complexes (Figure 7). On the other hand, the synergistic effect was only observed at 1:4 siRNA:polymer ratio even though the uptake of siRNA was similar at 1:4 and 1:8 siRNA:polymer ratios. A possible reason for ineffective siRNA treatment at 1:8 ratio could be the dissociation of complexes in cytoplasm; siRNA may have dissociated poorly from 
polymer at the higher 1:8 ratio because of strong binding between anionic siRNA and cationic polymer, resulting in poor efficacy of siRNA (Supplementary Figure 2). In addition, the size and $\zeta$ potential of complexes at different siRNA:polymer ratios may have contributed for the efficacy of siRNA treatment as well. The size of siRNA/1.2PEI-LA6 complexes decreased from $\sim 130$ to $\sim 63 \mathrm{~nm}$ as the polymer amount was increased from 1:2 to 1:8 ratios (Supplementary Figure 3). Similarly, the $\zeta$ potential has increased as the siRNA:polymer ratio increased. No significant difference was observed in size and $\zeta$-potential of complexes at 1:4 and 1:8 ratios, which may support the uptake of siRNA results as similar uptake was found at both of these ratios in MDA-MB-231 cells.

We have also determined how much damage the siRNAs are causing to normal cells since siRNA/polymer complexes will not be restricted to transfect only tumor cells when administered in vivo. As the results indicate, normal breast cells (MCF10A) seemed to be more sensitive to these complexes compared to endothelial (HUVEC) and bone marrow stromal cells (hBMSC; Figure 8). Moreover, the higher siRNA:polymer ratio used to prepare complexes was not effective to decrease cell growth of normal cells compared to lower ratio that inhibited the cell growth drastically in normal cells, which clearly showed how important it is to determine the specific formulation ratio carefully for siRNA therapy. The employed polymer (1.2PEI-LA6) did not have any cell-targeted moieties so that it is not surprising to observe its functionality in all of these adherent cells. Since no growth inhibition was found for the scrambled siRNA treated normal cells with all ratios, it was obvious that the polymeric delivery system was not toxic and the observed effect was due to specific siRNAs delivered. Furthermore, the cellular uptake of siRNA was found to be similar at all ratios in normal cells (Figure 7), which suggests that the polymer had successfully delivered siRNA into the cells at all ratios. However, the dissociation of polymer from siRNA in cytoplasm may have been higher at lower 1:2 siRNA:polymer ratio so that the effect of siRNA was evident in normal cells, and siRNA may have dissociated poorly from polymer at higher 1:8 ratio, resulting in poor efficacy of siRNA (Supplementary Figure 2). The 1:4 siRNA:polymer ratio showed synergistic effect with TTK and 
CDC20 siRNA in breast cancer cells (Figure 5), and the same ratio was not effective in normal cells except hBMSC that showed $\sim 30 \%$ cell death (Figure 8 ). Therefore, 1:4 ratio at total $30 \mathrm{nM}$ siRNA could be an effective dose to target TTK and CDC20 in breast cancer cells. The siRNA:polymer ratio could play a critical role under in vivo conditions at preclinical models, but this issue remains to be addressed at this stage; such an optimization with siRNA:polymer ratio might be necessary with the chosen molecular targets in vivo.

The synthesized polymer showed different efficacy in siRNA delivery to breast cancer and normal cells. Comparing the two breast cancer cells, we noted lower uptake of siRNA by MCF7 cells compared to MDA-MB-231 that may explain the lower silencing efficiencies (i.e., mRNA reduction based on RT-qPCR) and reduced response (i.e., cell growth inhibition) to specific siRNA delivery in MCF7 cells. The siRNA uptake was similar in HUVEC and hBMSC, suggesting no particular selectivity of polymer towards these normal cells. MCF10A, however, showed higher uptake of siRNA and were more responsive, leading to the selectivity of employed polymer to transfect breast cells efficiently compared to other cell-types. We have observed in the past that certain polymers can only transfect particular cell-lines, e.g. the polymer used to deliver siRNA to breast cancer cells has displayed poor efficacy in leukemia cells. ${ }^{51}$ This is expected to some extent since adherent cells probably possess different membrane structure than the non-adherent leukemic cells. For more effective clinical utility, it might be necessary to make the current polymers (without a targeting moiety) selective towards a particular cell-type. Perhaps, coating of complexes with polyethylene glycol $^{52}$ or hyaluronic acid ${ }^{53}$ could make the complexes selective for cancer cells (due to reduced uptake by initially encountered normal cells). The selectivity may arise from the choice of siRNA as well (i.e., selection of specific oncotargets), but with the three specific targets explored here, the selectivity was not universal and could only be partially achieved by fine-tuning of siRNA:polymer ratio used in formulating the nucleic acid complexes. Tailored polymers that can exclusively transfect malignant cells remain to be designed, synthesized and tested. 


\section{Conclusions}

The proteins TTK, CDC20 and survivin could be promising targets for siRNA therapy to decrease the proliferation of triple-negative breast cancer cells, such as MDA-MB-231 cells employed here. This study has indicated improved therapeutic efficacy of siRNAs by employing combinational siRNAs against cell cycle and anti-apoptosis proteins in breast cancer cells. The lipid-substituted polymers could serve as a viable platform for delivery of multiple siRNAs against critical targets, and co-delivery of siRNAs did not impair the desired silencing efficiency observed with individual siRNAs. However, the siRNA therapy with the chosen targets showed significant effects on nonmalignant cells in vitro. While the side-effects could be minimized with the optimization of siRNA:polymer ratio, more selective therapies (either polymers or siRNA against therapeutic targets) might be needed to target cancer cells solely.

\section{Acknowledgements}

Manoj Parmar is a recipient of Women and Children's Health Research Institute (WCHRI) Graduate Studentship Grant and Alberta Innovates-Health Solutions (AIHS) Graduate Studentship. This study was supported by operating grants from Canadian Breast Cancer Foundation (CBCF) and Natural Sciences and Engineering Council of Canada (NSERC).

\section{References}

1. Vici P, Pizzuti L, Natoli C, Gamucci T, Di Lauro L, Barba M, Sergi D, Botti C, Michelotti A, Moscetti L, Mariani L, Izzo F, D'Onofrio L, Sperduti I, Conti F, Rossi V, Cassano A, MaugeriSaccà M, Mottolese M, Marchetti P. Triple positive breast cancer: a distinct subtype? Cancer Treat Rev 2015;41:69-76. 
2. Hart CD, Migliaccio I, Malorni L, Guarducci C, Biganzoli L, Di Leo A. Challenges in the management of advanced, ER-positive, HER2-negative breast cancer. Nat Rev Clin Oncol $2015 ; 12: 541-552$.

3. Tinoco G, Warsch S, Glück S, Avancha K, Montero AJ. Treating breast cancer in the 21st century: emerging biological therapies. J Cancer 2013;4:117-132.

4. Foulkes WD, Smith IE, Reis-Filho JS. Triple-negative breast cancer. N Engl J Med 2010;363:1938-1948.

5. Dent R, Trudeau M, Pritchard KI, Hanna WM, Kahn HK, Sawka CA, Lickley LA, Rawlinson E, Sun P, Narod SA. Triple-negative breast cancer: clinical features and patterns of recurrence. Clin Cancer Res 2007; 13:4429-4434.

6. Reis-Filho JS, Tutt AN. Triple negative tumours: a critical review. Histopathology 2008;52:108118.

7. McManus MT, Sharp PA. Gene silencing in mammals by small interfering RNAs. Nat Rev Genet 2002;3:737-747.

8. Kim DH, Rossi JJ. Strategies for silencing human disease using RNA interference. Nat Rev Genet 2007;8:173-184.

9. Wilson RC, Doudna JA. Molecular mechanisms of RNA interference. Annu Rev Biophys $2013 ; 42: 217-239$.

10. Pecot CV, Calin GA, Coleman RL, Lopez-Berestein G, Sood AK. RNA interference in the clinic: challenges and future directions. Nat Rev Cancer 2011;11:59-67.

11. Bora RS, Gupta D, Mukkur TK, Saini KS. RNA interference therapeutics for cancer: challenges and opportunities. Mol Med Rep 2012;6:9-15.

12. Aliabadi HM, Landry B, Sun C, Tang T, Uludağ H. Supramolecular assemblies in functional siRNA delivery: where do we stand? Biomaterials 2012;33:2546-2569. 
13. Aliabadi HM, Landry B, Bahadur RK, Neamnark A, Suwantong O, Uludağ H. Impact of lipid substitution on assembly and delivery of siRNA by cationic polymers. Macromol Biosci $2011 ; 11: 662-672$.

14. KC RB, Kucharski C, Uludağ H. Additive nanocomplexes of cationic lipopolymers for improved non-viral gene delivery to mesenchymal stem cells. J Mat Chem B 2015;3:3972-3982.

15. Sandhu C, Slingerland J. Deregulation of the cell cycle in cancer. Cancer Detect Prev 2000;24:107118.

16. Malumbres M, Carnero A. Cell cycle deregulation: a common motif in cancer. Prog Cell Cycle Res $2003 ; 5: 5-18$

17. Mills GB, Schmandt R, McGill M, Amendola A, Hill M, Jacobs K, May C, Rodricks AM, Campbell S, Hogg D. Expression of TTK, a novel human protein kinase, is associated with cell proliferation. J Biol Chem 1992;267:16000-16006.

18. Hiruma Y, Sacristan C, Pachis ST, Adamopoulos A, Kuijt T, Ubbink M, von Castelmur E, Perrakis A, Kops GJ. Competition between MPS1 and microtubules at kinetochores regulates spindle checkpoint signaling. Science 2015;348:1264-1267.

19. Lo YL, Yu JC, Chen ST, Hsu GC, Mau YC, Yang SL, Wu PE, Shen CY. Breast cancer risk associated with genotypic polymorphism of the mitotic checkpoint genes: a multigenic study on cancer susceptibility. Carcinogenesis 2007;28:1079-1086.

20. Vaclavicek A, Bermejo JL, Wappenschmidt B, Meindl A, Sutter C, Schmutzler RK, Kiechle M, Bugert P, Burwinkel B, Bartram CR, Hemminki K, Försti A. Genetic variation in the major mitotic checkpoint genes does not affect familial breast cancer risk. Breast Cancer Res Treat 2007; 106:205-213.

21. Ahn CH, Kim YR, Kim SS, Yoo NJ, Lee SH. Mutational analysis of TTK gene in gastric and colorectal cancers with microsatellite instability. Cancer Res Treat 2009;41:224-228. 
22. Kaistha BP, Honstein T, Müller V, Bielak S, Sauer M, Kreider R, Fassan M, Scarpa A, Schmees C, Volkmer H, Gress TM, Buchholz M. Key role of dual specificity kinase TTK in proliferation and survival of pancreatic cancer cells. Br J Cancer 2014;111:1780-1787.

23. Kimata Y, Baxter JE, Fry AM, Yamano H. A role for the Fizzy/Cdc20 family of proteins in activation of the APC/C distinct from substrate recruitment. Mol Cell 2008;32:576-583.

24. Tipton AR, Ji W, Sturt-Gillespie B, Bekier ME, Wang K, Taylor WR, Liu ST. Monopolar spindle 1 (MPS1) kinase promotes production of closed MAD2 (C-MAD2) conformer and assembly of the mitotic checkpoint complex. J Biol Chem 2013;288:35149-35158.

25. Maciejowski J, George KA, Terret ME, Zhang C, Shokat KM, Jallepalli PV. Mps1 directs the assembly of Cdc20 inhibitory complexes during interphase and mitosis to control $\mathrm{M}$ phase timing and spindle checkpoint signaling. J Cell Biol 2010;190:89-100.

26. King KL, Cidlowski JA. Cell cycle regulation and apoptosis. Annu Rev Physiol 1998;60:601-617.

27. Reed JC. Mechanisms of apoptosis. Am J Pathol 2000;157:1415-1430.

28. Small S, Keerthivasan G, Huang Z, Gurbuxani S, Crispino JD. Overexpression of survivin initiates hematologic malignancies in vivo. Leukemia 2010;24:1920-1926.

29. Shi Z, Liang YJ, Chen ZS, Wang XH, Ding Y, Chen LM, Fu LW. Overexpression of Survivin and XIAP in MDR cancer cells unrelated to P-glycoprotein. Oncol Rep 2007;17:969-976.

30. Peroukides S, Bravou V, Alexopoulos A, Varakis J, Kalofonos H, Papadaki H. Survivin overexpression in HCC and liver cirrhosis differentially correlates with p-STAT3 and E-cadherin. Histol Histopathol 2010;25:299-307.

31. Sah NK, Khan Z, Khan GJ, Bisen PS. Structural, functional and therapeutic biology of survivin. Cancer Lett 2006;244:164-171.

32. Carvalho A, Carmena M, Sambade C, Earnshaw WC, Wheatley SP. Survivin is required for stable checkpoint activation in taxol-treated HeLa cells. J Cell Sci 2003;116:2987-2998. 
33. Lens SM, Wolthuis RM, Klompmaker R, Kauw J, Agami R, Brummelkamp T, Kops G, Medema RH. Survivin is required for a sustained spindle checkpoint arrest in response to lack of tension. EMBO J 2003;22:2934-2947.

34. Bahadur KC, Landry B, Aliabadi HM, Lavasanifar A, Uludağ H. Lipid substitution on low molecular weight $(0.6-2.0 \mathrm{kDa})$ polyethylenimine leads to a higher zeta potential of plasmid DNA and enhances transgene expression. Acta Biomater 2011;7:2209-2217.

35. Remant Bahadur KC, Uludağ H. A comparative evaluation of disulfide-linked and hydrophobically-modified PEI for plasmid delivery. J Biomater Sci Polym Ed 2011;22:873-892.

36. Jiang H, Secretan C, Gao T, Bagnall K, Korbutt G, Lakey J, Jomha NM. The development of osteoblasts from stem cells to supplement fusion of the spine during surgery for AIS. In: Uyttendaele D, Dangerfield PH, editors. Studies in Health Technology and Informatics: Research in Spinal Deformities. Amsterdam, The Netherlands: IOS Press; 2006. p 467-472.

37. Sumantran VN. Cellular chemosensitivity assays: an overview. Methods Mol Biol 2011;731:219236.

38. Moghimi SM, Symonds P, Murray JC, Hunter AC, Debska G, Szewczyk A. A two-stage poly(ethylenimine)-mediated cytotoxicity: implications for gene transfer/therapy. Mol Ther 2005;11:990-995.

39. Parmar MB, Aliabadi HM, Mahdipoor P, Kucharski C, Maranchuk R, Hugh JC, Uludağ H. Targeting cell cycle proteins in breast cancer cells with siRNA by using lipid-substituted polyethylenimines. Front Bioeng Biotechnol 2015;3:14.

40. Maire V, Baldeyron C, Richardson M, Tesson B, Vincent-Salomon A, Gravier E, Marty-Prouvost B, De Koning L, Rigaill G, Dumont A, Gentien D, Barillot E, Roman-Roman S, Depil S, Cruzalegui F, Pierré A, Tucker GC, Dubois T. TTK/hMPS1 is an attractive therapeutic target for triple-negative breast cancer. PLoS One 2013;8:e63712. 
41. Liang XD, Dai YC, Li ZY, Gan MF, Zhang SR, Yin-Pan, Lu HS, Cao XQ, Zheng BJ, Bao LF, Wang DD, Zhang LM, Ma SL. Expression and function analysis of mitotic checkpoint genes identifies TTK as a potential therapeutic target for human hepatocellular carcinoma. PLoS One 2014;9:e97739.

42. Dahlman KB, Parker JS, Shamu T, Hieronymus H, Chapinski C, Carver B, Chang K, Hannon GJ, Sawyers CL. Modulators of prostate cancer cell proliferation and viability identified by shorthairpin RNA library screening. PLoS One 2012;7:e34414.

43. Malefyt AP, Wu M, Vocelle DB, Kappes SJ, Lindeman SD, Chan C, Walton SP. Improved asymmetry prediction for short interfering RNAs. FEBS J 2014;281:320-330.

44. Noland CL, Doudna JA. Multiple sensors ensure guide strand selection in human RNAi pathways. RNA 2013;19:639-648.

45. Kim DH, Behlke MA, Rose SD, Chang MS, Choi S, Rossi JJ. Synthetic dsRNA Dicer substrates enhance RNAi potency and efficacy. Nat Biotechnol 2005;23:222-226.

46. Montazeri Aliabadi H, Landry B, Mahdipoor P, Uludağ H. Induction of apoptosis by survivin silencing through siRNA delivery in a human breast cancer cell line. Mol Pharm 2011;8:18211830.

47. Pietenpol JA, Stewart ZA. Cell cycle checkpoint signaling: cell cycle arrest versus apoptosis. Toxicology 2002;181-182:475-481.

48. Castedo M, Perfettini JL, Roumier T, Andreau K, Medema R, Kroemer G. Cell death by mitotic catastrophe: a molecular definition. Oncogene 2004;23:2825-2837.

49. Harley ME, Allan LA, Sanderson HS, Clarke PR. Phosphorylation of Mcl-1 by CDK1-cyclin B1 initiates its Cdc20-dependent destruction during mitotic arrest. EMBO J 2010;29:2407-2420.

50. Saintigny Y, Dumay A, Lambert S, Lopez BS. A novel role for the Bcl-2 protein family: specific suppression of the RAD51 recombination pathway. EMBO J 2001;20:2596-2607. 
51. Valencia-Serna J, Gul-Uludağ H, Mahdipoor P, Jiang X, Uludağ H. Investigating siRNA delivery to chronic myeloid leukemia K562 cells with lipophilic polymers for therapeutic BCR-ABL downregulation. J Control Release 2013;172:495-503.

52. Mishra P, Nayak B, Dey RK. PEGylation in anti-cancer therapy: An overview. Asian Journal of Pharmaceutical Sciences 2015;11:337-348.

53. Martens TF, Remaut K, Deschout H, Engbersen JF, Hennink WE, van Steenbergen MJ, Demeester J, De Smedt SC, Braeckmans K. Coating nanocarriers with hyaluronic acid facilitates intravitreal drug delivery for retinal gene therapy. J Control Release 2015;202:83-92.

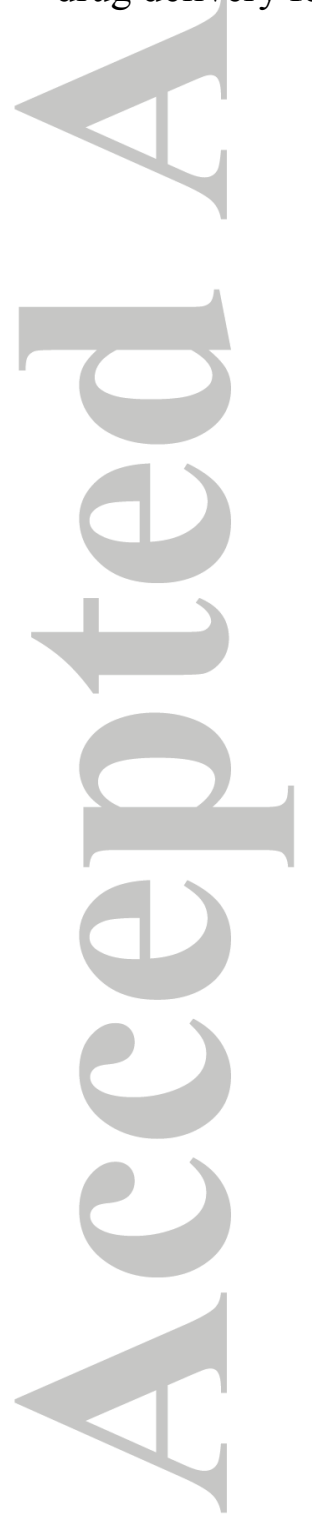

John Wiley2e Sons, Inc. 


\section{Figure Legends}

Figure 1: Screening of polymeric carriers using lipid-substituted PEIs in MDA-MB-231 cells. Modified PEIs were synthesized using linoleic acid (LA) with different feed ratios. The synthesized polymers were designated based on the molecular weight of PEI (0.6, 1.2 and $2.0 \mathrm{kDa})$ backbone used for modification, followed by the substituted lipid moiety and the feed ratio of lipid/PEI during the synthesis of the polymers. The inhibition of cell growth by $40 \mathrm{nM}$ siRNA against TTK-1 (A) and CDC20 (B) at 1:6 siRNA:polymer ratio was assessed with MTT assay. Lipofectamine ${ }^{\circledR} 2000$ (Thermo Fisher Scientific) was used as a positive control with 1:1 siRNA:lipofectamine ratio. Scrambled siRNA (CsiRNA) was used as a negative control. The results were presented by taking non-treated cells as $100 \%$ cell growth. Asterisks represent the significant cell growth inhibition by TTK-1 or CDC20 siRNA compared to CsiRNA $(p<0.05)$.

Figure 2: Physicochemical characterization and cellular uptake of siRNA by flow cytometry. (A) Size (i) and surface charge (ii; $\zeta$-potential) of siRNA/polymer complexes were determined using polymers with different degree of lipid-substitutions in $1.2 \mathrm{kDa}$ PEI. The complexes were prepared with $0.6 \mu \mathrm{g}$ of scrambled siRNA at 1:6 and 1:1 siRNA:polymer and siRNA:Lipofectamine ratios, respectively. (B) FAM-labeled scrambled siRNA was used to determine cellular uptake of siRNA/polymer complexes at $40 \mathrm{nM}$ siRNA with $1: 6$ and $1: 1$ siRNA:polymer and siRNA:Lipofectamine ratios, respectively. Non-labeled scrambled siRNA was used as a control to investigate auto-fluorescence of complexes. The mean fluorescence (i) and FAM-positive cell population (ii) was determined for all siRNA carriers. 
Figure 3: Targeting TTK with various siRNAs in MDA-MB-231 and MCF7 cells. TTK-1, TTK-2, TTK-3 and TTK-4 siRNAs were delivered with 20 (A), 40 (B) and 60 nM (C) siRNA, while TTK-5 and TTK-6 siRNAs (D) were delivered with 40 and $60 \mathrm{nM}$ siRNA at 1:4 siRNA:1.2PEI-LA6 ratios. The inhibition of cell growth was assessed by MTT assay and scrambled siRNA (CsiRNA) was used as a negative control. Asterisks represent the significant cell growth inhibition by specific siRNA compared to CsiRNA $(p<0.05)$.

Figure 4: RT-qPCR for MDA-MB-231 (A) and MCF7 (B) cells treated with TTK-1 and CDC20 siRNAs. TTK-1 and CDC20 were targeted with $60 \mathrm{nM}$ siRNA at 1:4 siRNA:1.2PEI-LA6 ratio. RTqPCR was performed after 24 and 48 hrs of transfection. Scrambled siRNA (CsiRNA) was used as a negative control. Asterisks represent the significant reduction in the quantity of transcripts compared to CsiRNA $(p<0.05)$.

Figure 5: Combinational siRNA delivery against TTK-1 (referred as TTK), CDC20 and survivin in MDA-MB-231 (A) and MCF7 (B) cells. Combination was performed with total $30 \mathrm{nM}(15+15 \mathrm{nM}$ each) siRNA at 1:2, 1:4 and 1:8 siRNA:1.2PEI-LA6 ratio. Scrambled siRNA (CsiRNA) was used as a negative control. Asterisks represent the significant cell growth inhibition with combinational siRNA therapy compared to CsiRNA and specific siRNA alone $(p<0.05)$.

Figure 6: RT-qPCR for MDA-MB-231 and MCF7 cells treated with combinational siRNAs. Cells were transfected with total $30 \mathrm{nM}(15+15 \mathrm{nM}$ each) and $60 \mathrm{nM}(30+30 \mathrm{nM}$ each) siRNA at 1:4 siRNA:1.2PEI-LA6 ratio. RT-qPCR was performed after 24 hrs of transfection. Scrambled siRNA (CsiRNA) was used as a negative control. Asterisks represent the significant reduction in the quantity of transcripts compared to CsiRNA $(p<0.05)$. 
Figure 7: Cellular uptake of siRNA by flow cytometry. FAM-labeled scrambled siRNA was used to determine cellular uptake of siRNA/polymer complexes at $30 \mathrm{nM}$ siRNA with 1:2, 1:4 and 1:8 siRNA:polymer ratios. Non-labeled scrambled siRNA was used as a control to investigate autofluorescence of complexes at $30 \mathrm{nM}$ siRNA with 1:2 ratio. The mean fluorescence (A) and FAMpositive cell population (B) was determined for breast cancer and normal cells.

Figure 8: Combinational siRNA delivery against TTK, CDC20 and survivin in non-malignant cells. Combination was performed with total $30 \mathrm{nM}(15+15 \mathrm{nM}$ each) siRNA at 1:2, 1:4 and 1:8 siRNA:1.2PEI-LA6 ratio in MCF10A (A), HUVEC (B) and hBMSC (C) cells. Scrambled siRNA (CsiRNA) was used as a negative control. A heat-map (D) represents specific cell growth inhibition by combinational siRNA therapy compared to CsiRNA in breast cancer and normal cells.

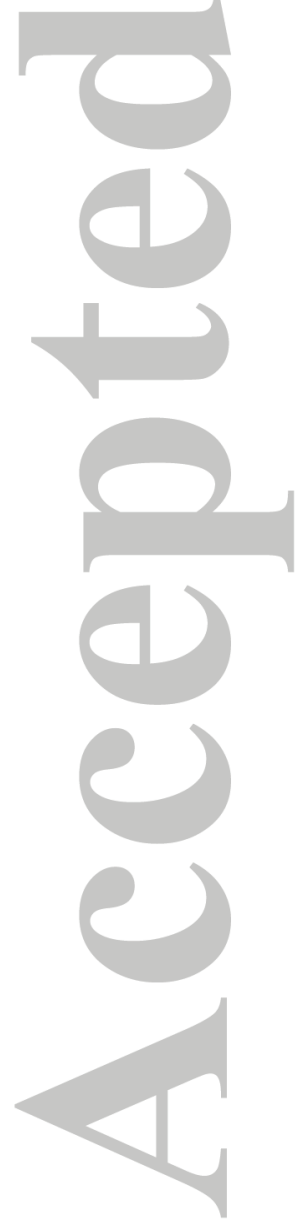

John Wileyß@ Sons, Inc. 
Figure 1

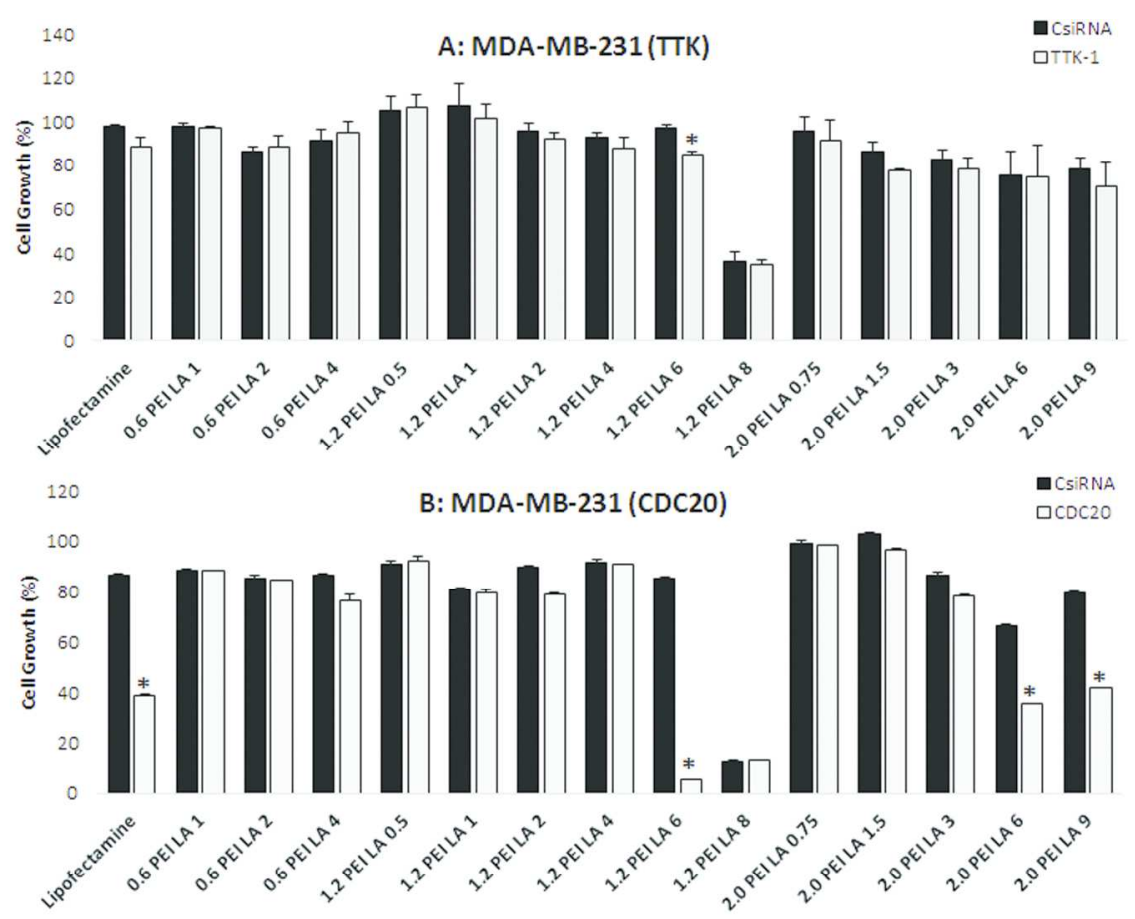

$215 \times 279 \mathrm{~mm}(300 \times 300 \mathrm{DPI})$

John Wiley \& Sons, Inc.

This article is protected by copyright. All rights reserved. 

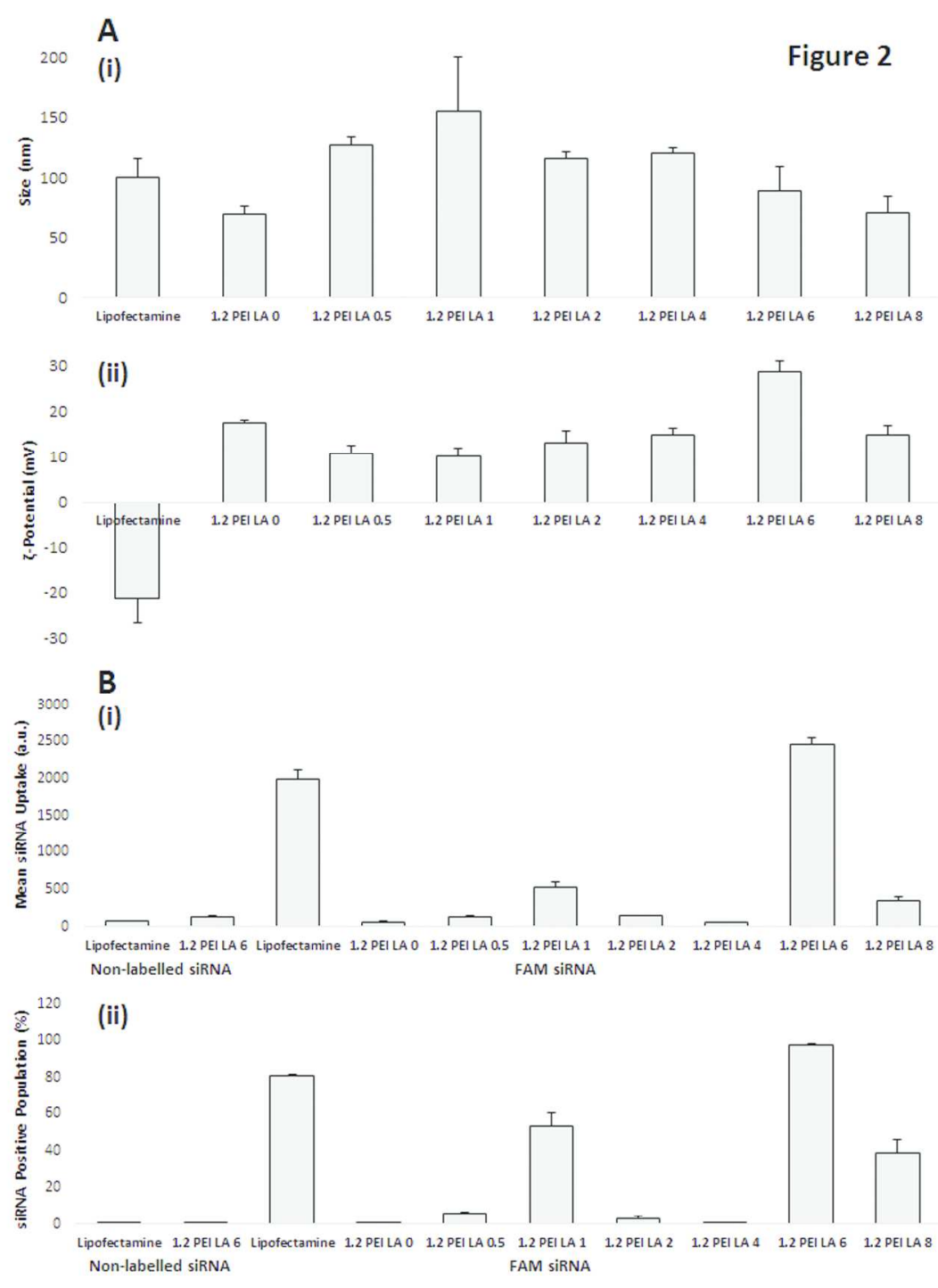

$215 \times 279 \mathrm{~mm}(300 \times 300$ DPI $)$

John Wiley \& Sons, Inc.

This article is protected by copyright. All rights reserved. 
Figure 3
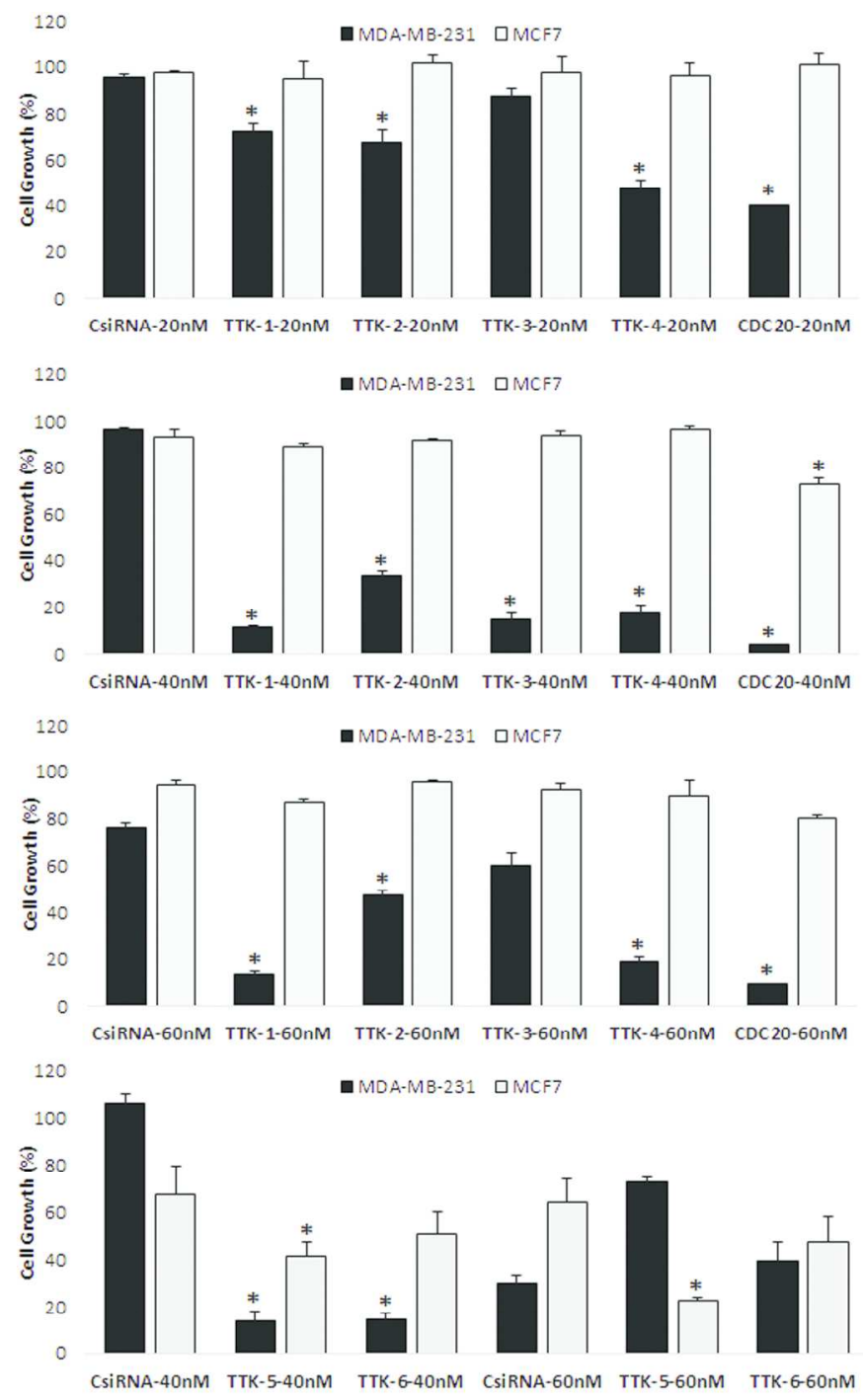

$215 \times 279 \mathrm{~mm}(300 \times 300 \mathrm{DPI})$

John Wiley \& Sons, Inc.

This article is protected by copyright. All rights reserved. 
Figure 4

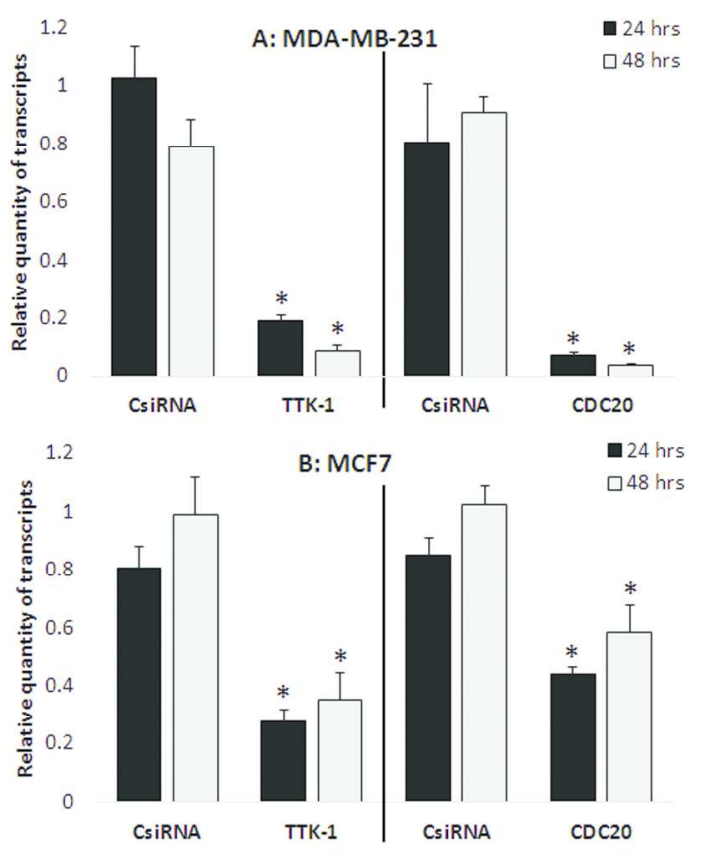

$215 \times 279 m m(300 \times 300$ DPI $)$

John Wiley \& Sons, Inc.

This article is protected by copyright. All rights reserved. 
Figure 5

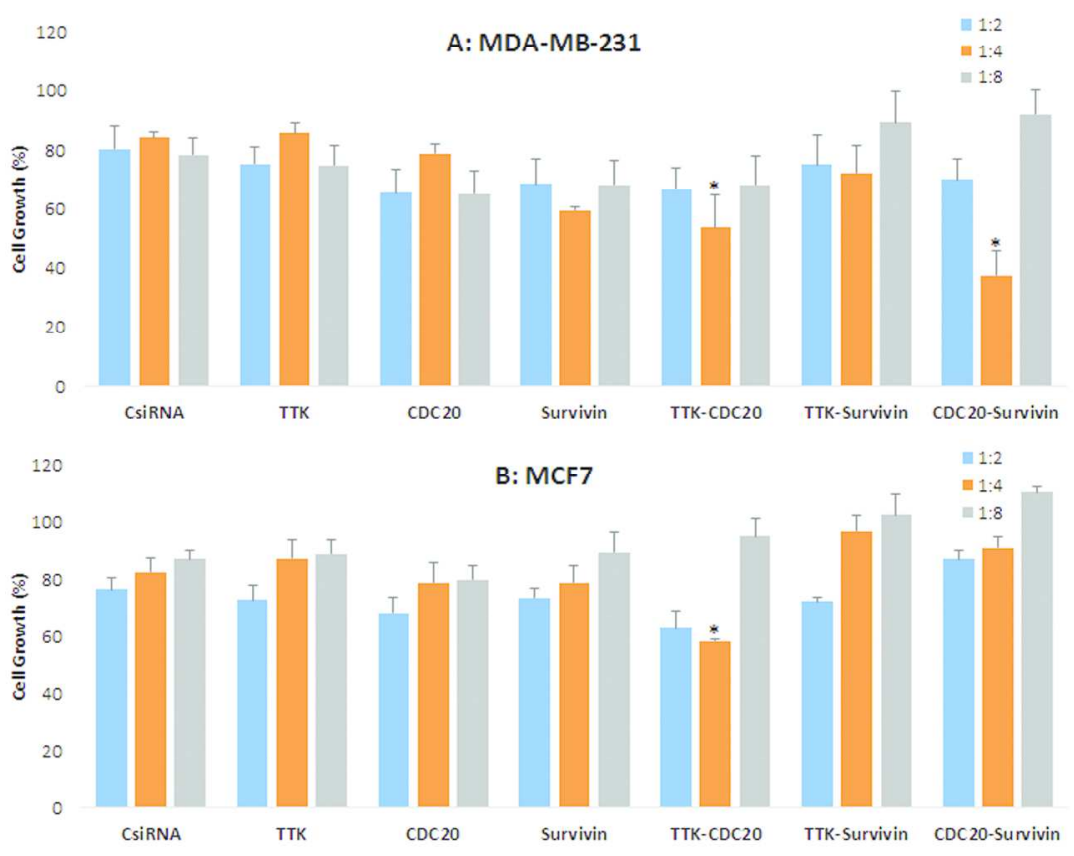

$215 \times 279 \mathrm{~mm}(300 \times 300 \mathrm{DPI})$

John Wiley \& Sons, Inc.

This article is protected by copyright. All rights reserved. 


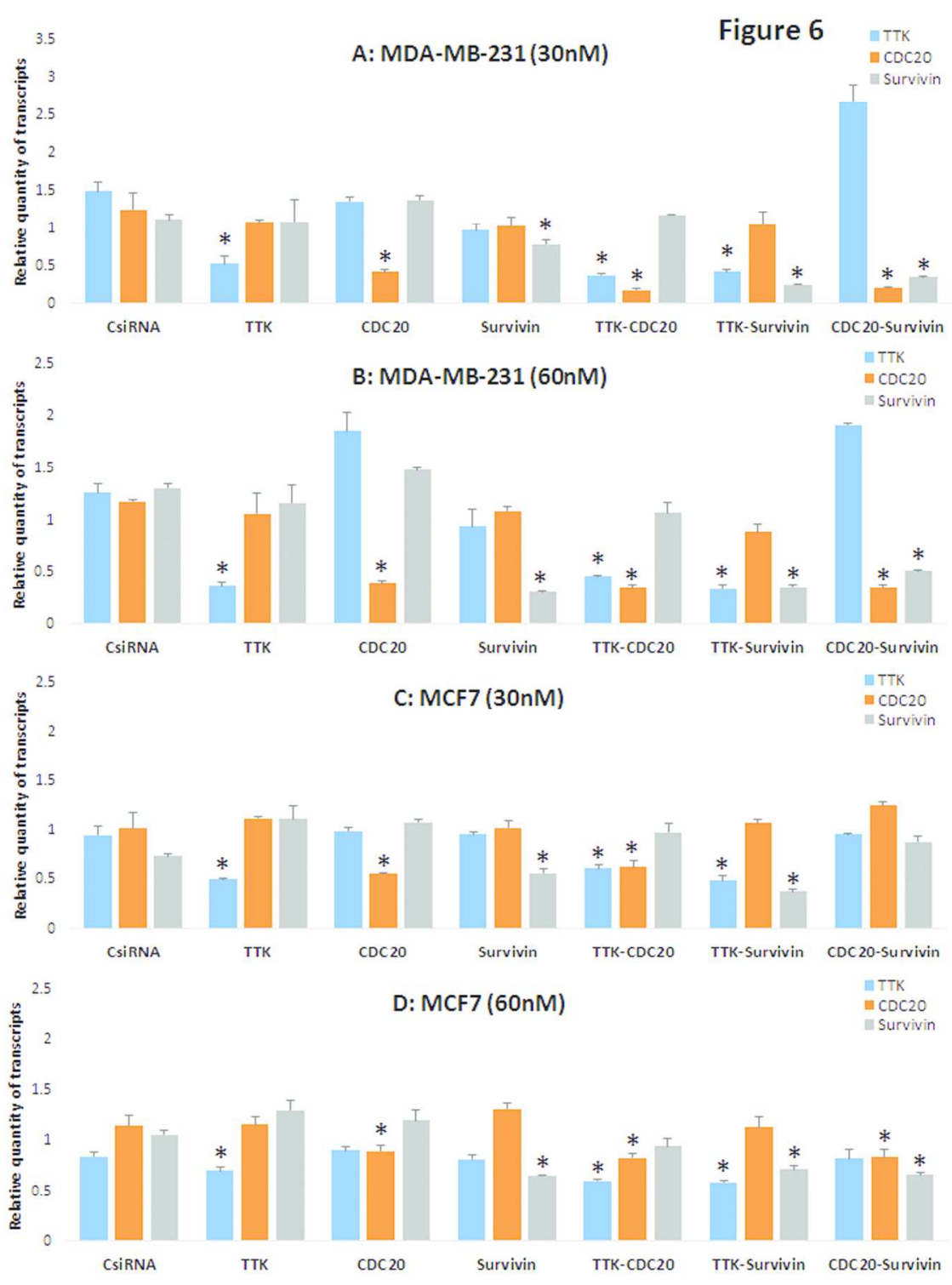

$215 \times 279 \mathrm{~mm}(300 \times 300 \mathrm{DPI})$

John Wiley \& Sons, Inc.

This article is protected by copyright. All rights reserved. 
Figure 7

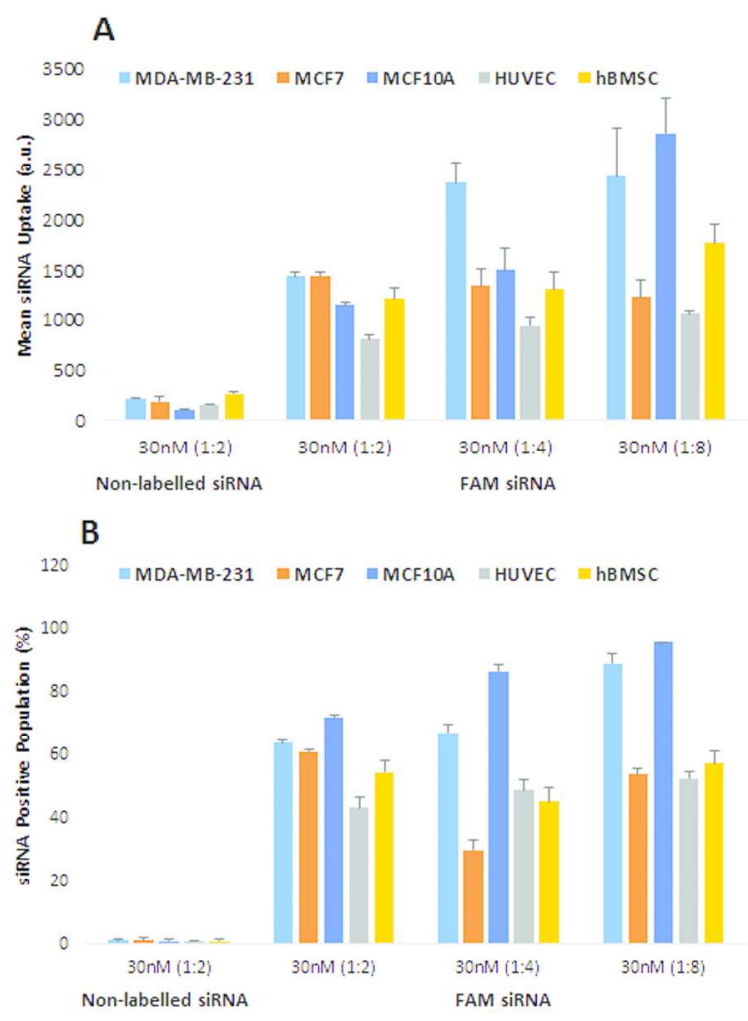

$215 \times 279 \mathrm{~mm}(300 \times 300 \mathrm{DPI})$

John Wiley \& Sons, Inc.

This article is protected by copyright. All rights reserved. 


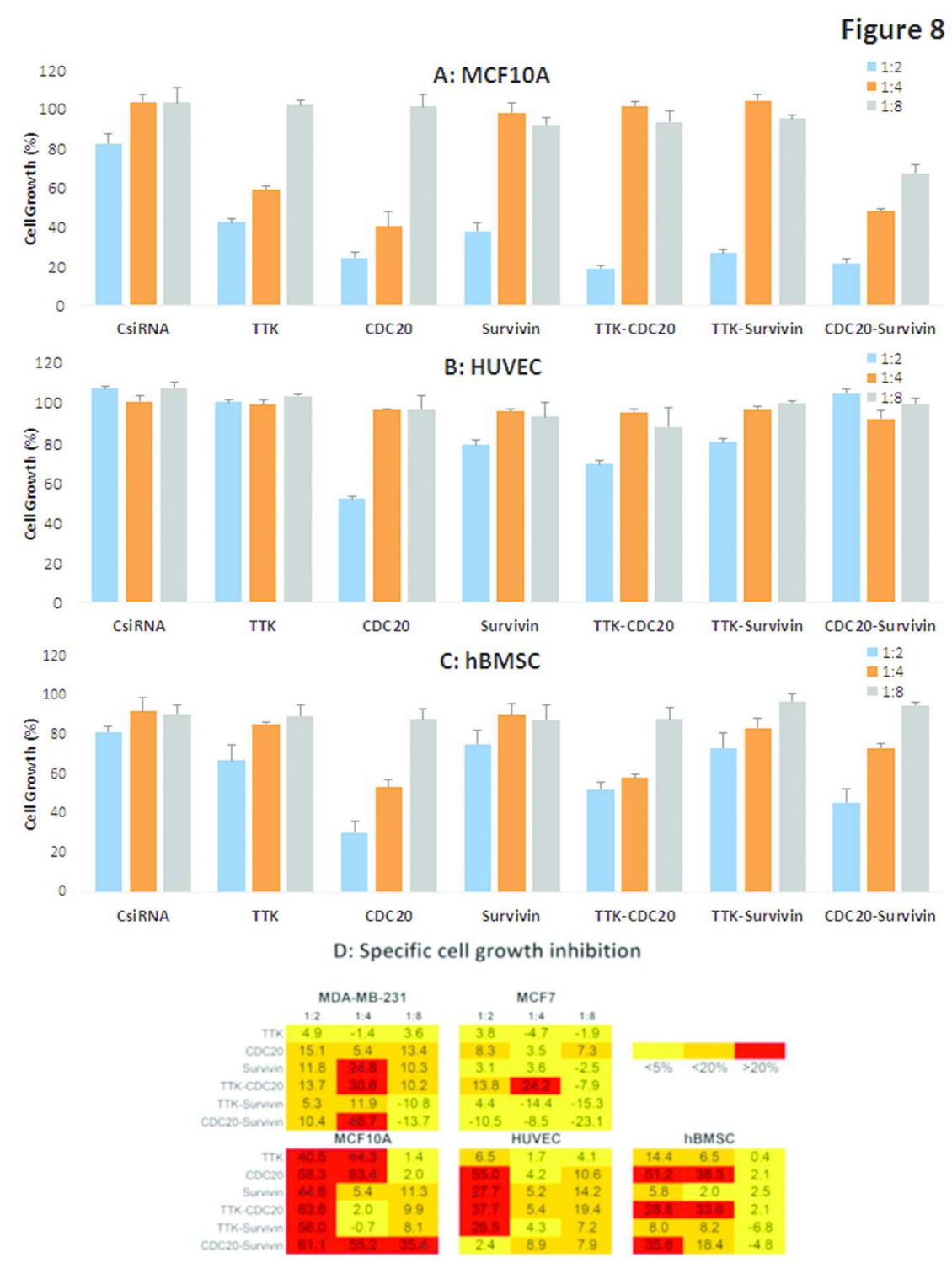

$215 \times 279 \mathrm{~mm}(300 \times 300 \mathrm{DPI})$

John Wiley \& Sons, Inc.

This article is protected by copyright. All rights reserved. 